\title{
Recurrence of Pallister-Hall syndrome in two sibs
}

\author{
H M Thomas, P J Todd, D Heaf, A E Fryer
}

\begin{abstract}
We report the first definite sib recurrence of Pallister-Hall syndrome in a family without a cytogenetically visible chromosome abnormality. The father of these two sibs was born with nearly identical digital abnormalities and could represent either mild expression or gonosomal mosaicism for a dominant gene.
\end{abstract}

( $\mathcal{F}$ Med Genet 1994;31:145-147)

Pallister-Hall syndrome is a multiple congenital anomaly syndrome characterised by the presence of a congenital hypothalamic hamartoblastoma. Most published cases have been sporadic though the features do overlap strongly with some recessive disorders. We report a family with two affected sibs whose father has digital abnormalities very similar to those of his affected children. We postulate that he could represent either very mild expression or gonosomal mosaicism for a dominant gene and that most cases of this disorder could represent new dominant mutations.

\section{Case report}

CASE 1

A female infant, the first child of unrelated parents, was born at term weighing $3130 \mathrm{~g}$, head circumference $35 \mathrm{~cm}$. Multiple problems were noted at birth including choanal atresia, bifid epiglottis, and a cleft upper larynx with posterior web in the subglottic area. A CT scan of the thorax showed that the angle of the carina was almost $180^{\circ}$. Facially she had a short nose with depressed nasal bridge and anteverted nares (fig 1) and her ear lobes were anteverted. Her eyes were normal. There was bilateral hexadactyly with osseous $2 / 3$ syndactyly of the right hand which may have represented an insertional type of polydactyly (fig 2). There was mild soft tissue syndactyly of the left hand. All fingers appeared slightly short and tapering. In the feet, there was talipes bilaterally but no polydactyly. The anus and genitalia were normal, though on $x$ ray, the sacrum appeared hypoplastic. There was no evidence of a generalised skeletal dysplasia.

Subsequently she developed signs of hypopituitarism, the cause of which was not evident on a cranial CT scan. She required endocrine replacement therapy but despite this her subsequent growth was very poor and she had recurrent problems with upper airways obstruction eventually necessitating a tracheostomy. She also required a gastrostomy

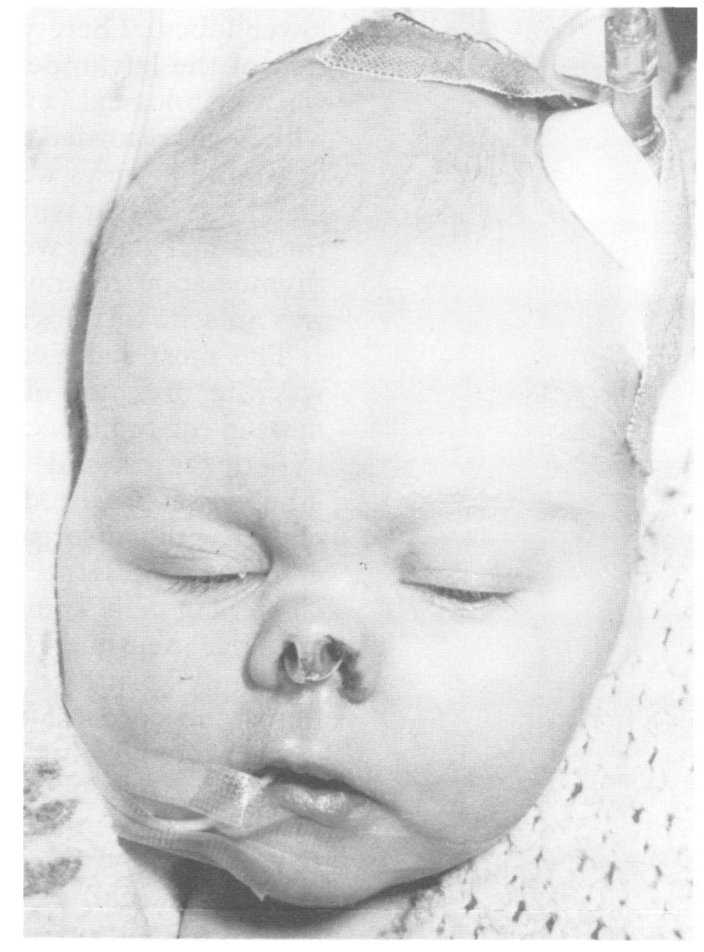

Figure 1 Case 1: facial appearance.
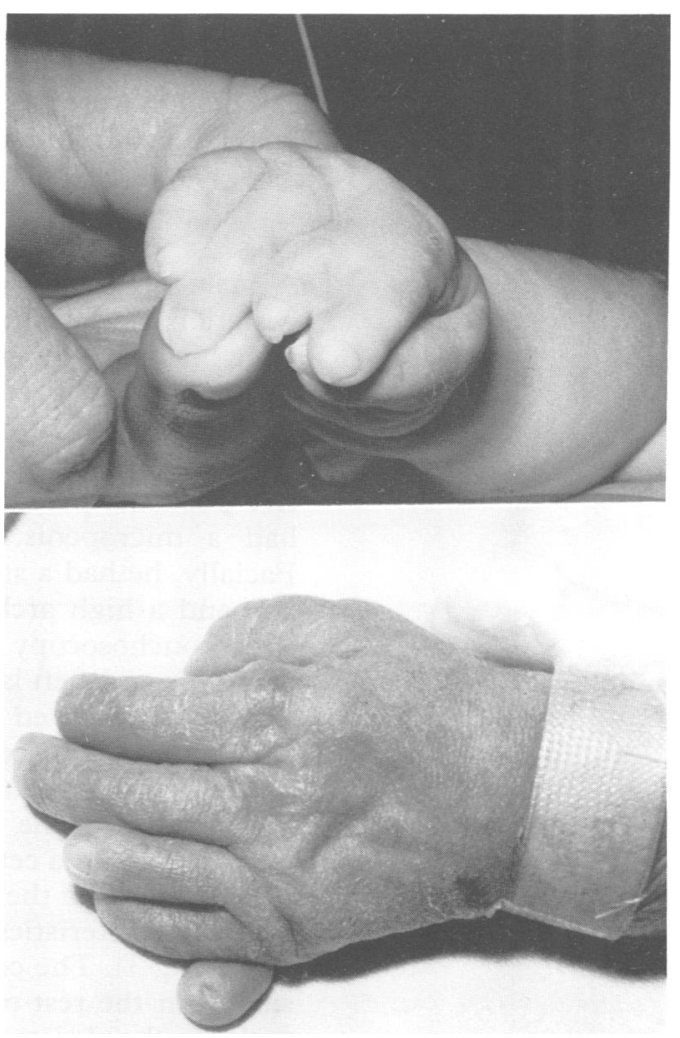

Figure 2 (Above) Insertional polydactyly in case 1. (Below) Postaxial polydactyly in case 2 .

\author{
Received 28 May 1993 \\ Revised version accepted for \\ publication 7 Septembe \\ 1993 \\ Correspondence to \\ Dr Fryer, Regional Clinical \\ Genetics Service, Royal \\ Liverpool University \\ Hospital, PO Box 147
}


because of feeding difficulties but she eventually died at 12 months of age after a respiratory infection. At this age she was only $55 \mathrm{~cm}$ long and weighed $6.6 \mathrm{~kg}$ with a head circumference of $37 \mathrm{~cm}$. Her chromosomes were normal.

At necropsy, several additional findings were noted including a tracheal diverticulum and a small right middle lobe of the lungs with incomplete separation of the right upper and lower lobes. There was also deficient separation of the left upper and lower lobes. There was histological evidence of pneumonitis which was recorded as the cause of death. The heart and kidneys were normal. The pituitary gland was absent with a rudimentary stalk and the adrenal glands were markedly fibrotic. The thymus appeared normal macroscopically but was aplastic histologically.

The most significant finding diagnostically was the presence of a $2 \times 2 \mathrm{~cm}$ soft nodular mass in the brain occupying the position of the hypothalamus and replacing it completely. The mass consisted predominantly of grey matter with a disorganised structure including a mixture of large and small neurones and clusters of cells with the morphology of small granular neurones. There were also a few randomly scattered bundles of myelinated fibres and cords of ependymal cells, some of which were forming tubules. The appearances were those of a hypothalamic hamartoma and this had not been detected on cranial CT scan. Examination of the rest of the brain showed that the frontal, parietal, and occipital lobes appeared disproportionately small with respect to the temporal lobes. The unci were featureless and the olfactory tracts were absent. There was a generalised reduction of bulk of the white matter and the corpus callosum was abnormally thin. The brain stem and cerebellum were normal. A diagnosis of Pallister-Hall syndrome was made.

CASE 2

A male sib of case 1 was born at 30 weeks' gestation and required respiratory support after birth for upper airways obstruction. He also had 4/5 syndactyly of the right hand with postaxial polydactyly of both hands and short fourth and fifth digits (fig 2). There was abortive postaxial polydactyly of the left foot. He had a micropenis. The anus was normal. Facially, he had a small jaw, mouth, and tongue and a high arched palate. Laryngoscopy and bronchosocopy showed a bifid uvula and epiglottis and cleft larynx. The left main bronchus was narrowed and the right main bronchus appeared to contain a blind ending pit. There was mild choanal narrowing.

Subsequently he was shown to have hypopituitarism and a cerebral MRI scan showed a $2 \times 2 \mathrm{~cm}$ mass in the hypothalamic region with signal characteristics identical to normal brain tissue (fig 3). The cerebellum appeared rather small but the rest of the brain appeared normal. On the skeletal survey, the left hand had an accessory digit with no formed bone element, a hypoplastic middle finger, and a hypo-

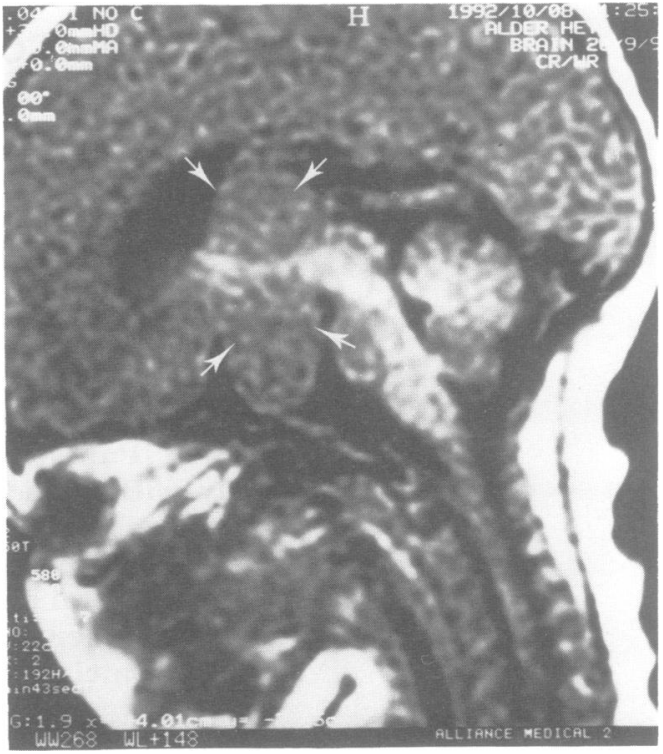

Figure 3 Case 2. MRI scan T1 weighted image midline sagittal section showing a hypothalamic tumour.

plastic fourth metacarpal. In the right hand the first metacarpal was hypoplastic and joined at its base to the second metacarpal. There was an accessory index finger with formed phalanges but no metacarpal. In the feet, the left fifth toe was abnormal with a laterally deviated fifth metatarsal. There were no other anomalies in the rest of the survey and, in particular, no evidence of a generalised skeletal dysplasia. The chromosomes were normal.

The abnormalities in this boy are almost identical to those in his sib and compatible with Pallister-Hall syndrome. During follow up, he showed reduced growth and delayed development and he died suddenly at $9 \frac{1}{2}$ months of age after a respiratory infection.

Examination of the parents of cases 1 and 2 showed that the children's father was born with nearly complete $4 / 5$ cutaneous syndactyly of the right hand and postaxial polydactyly of both hands. He had no other abnormalities. Both parents have normal chromosomes.

\section{Discussion}

Pallister-Hall syndrome (congenital hypothalamic hamartoblastoma syndrome) was described in 1980 though some possible cases were published earlier and these cases are reviewed by Iafolla et al and Verloes et al. ${ }^{2}$ The four main components of the syndrome are postaxial polydactyly, imperforate anus, hypopituitarism, and a hypothalamic hamartoblastoma, though these features are variable. Additional reported features in these patients include a short nose with flat nasal bridge, abnormal ears, microglossia, micrognathia, bifid epiglottis and cleft larynx, lung segmentation abnormalities, congenital heart disease, and renal ectopia. Some patients appear to have had short limbs. Our cases clearly have most of the features of the syndrome including all of the main components except for anal anomalies which were only recorded in seven out of 13 cases reviewed by Iafolla et al. ${ }^{1}$ Our 
case 1 had a hypoplastic sacrum noted on $x$ ray which is unusual, though case 1 of Graham et $a l^{3}$ had partial fusion of L5 and S1 vertebral bodies. One new feature in our patients is the presence of choanal atresia/stenosis. The failure of CT scanning to detect the tumour in case 1 is well recognised and MRI is now regarded as the method of choice for diagnosis. ${ }^{1}$ Most reported cases have died in the newborn period, possibly from hypoadrenalism but longer term survival may be possible with appropriate endocrine management.

The presence of a hypothalamic hamartoblastoma has been considered to be an obligatory manifestation of the condition, ${ }^{1}$ although this view has been questioned recently by Finnegan et $a l,{ }^{6}$ who described two patients with some features of the syndrome and diencephalic abnormalities but without hamartoblastomas. The features in their patients do, however, show considerable overlap with MeckelGruber syndrome and orofaciodigital syndrome type VI. These cases and that of Meunke et $a l^{5}$ clearly illustrate the difficulty in distinguishing Pallister-Hall from those two syndromes and several others, notably SmithLemli-Opitz type 2, hydrolethalus, and holoprosencephaly-polydactyly (pseudotrisomy 13).

The presence of a hypothalamic hamartoblastoma could be regarded as a means of distinguishing Pallister-Hall syndrome but this view is challenged by Verloes et al. ${ }^{2}$ They described a patient with features of holoprosencephaly-polydactyly who had a hypothalamic hamartoma and review four other case reports where a hypothalamic tumour has been described in patients not considered to have the Pallister-Hall syndrome. Those authors concluded that a child with syndromal hypothalamic hamartoblastoma cannot be reliably diagnosed as Pallister-Hall as opposed to one of these other multiple anomaly syndromes.

The recurrence risk in Pallister-Hall syndrome has been thought to be low in view of the fact that almost all cases have been sporadic. More recently, there has been some concern that the disorder may be autosomal recessive in view of the similarities with the above recessive syndromes and the disorder is listed as autosomal recessive in the London Dysmorphology Database.

The only published familial cases described as Pallister-Hall syndrome are the reports by Graham $e t a l^{3}$ and Encha-Razavi et al. ${ }^{6}$ Case 1 reported by Graham $e t a l^{\beta}$ is interesting as the mother of the affected child had had three miscarriages and she had had a sister who had died at 17 hours of age and was described as having a flat nasal bridge, microglossia, and hexadactyly. Chromosomal studies in the child's mother were normal. Family 1 reported by Encha-Razavi et $a l^{6}$ is unusual in that the two affected sibs had a skeletal dysplasia (micromelia, short ribs, short, broad long bones, irregular metaphyses, and mild curvature of the radii and ulnae with short broad phalanges and narrow cervical vertebrae) in addition to features of a hypothalamic hamartoma syndrome and so may represent a separate entity. Although some patients with Pallister-Hall have reportedly had short limbs, none has had the appearances described by Encha-Razavi et $a l^{6}$

In addition to the above cases, Golabi et al reported a child with hypothalamic hamartomas and multiple anomalies who had combined $3 p$ trisomy and $7 q$ monosomy. ${ }^{7}$ The child's father was a balanced carrier and the couple had had a previous child with similar abnormalities who was thought likely to have had the same unbalanced karyotype. Patient 2 of Pallister $e t a l^{8}$ was reported to have an extra small metacentric marker chromosome in one out of 50 cells but the significance of this is uncertain and those authors preferred to consider a possible teratogenic aetiology. No other chromosomal abnormalities have been reported.

The family which we report therefore represents the first definite sib recurrence in Pallister-Hall syndrome in the absence of a cytogenetically visible chromosome abnormality and could support the suggestion that the disorder is autosomal recessive, at least in some cases. The findings in the father of our patients do, however, promote another intriguing possibility. His digital abnormalities are strikingly similar to those of his children which suggests that he might represent either very mild expression or gonosomal mosaicism for a dominant gene. The published sporadic cases of Pallister-Hall could then represent new dominant mutations and this disorder may then be a separate entity from the recessive disorders from which it is difficult to distinguish. Whichever mechanism is involved, caution should be exhibited in counselling families about recurrence risks in this syndrome.

1 Iafolla K, Fratkin JD, Spiegel PK, Cohen MM, Graham JM. Case report and delineation of the congenital hypothalamic hamartoblastoma syndrome (Pallister-Hall syndrome). $\mathrm{Am}$ f Med Genet 1989;33:489-99.

2 Verloes A, Gillerot Y, Langhendries JP, Fryns JP, Kouerloes A, Gillerot Y, Langhendries JP, Fryns JP, Kou-
lischer L. Variability versus heterogeneity in syndromal hypothalamic hamartoblastoma and related disorders: review and delineation of the cerebro-acro-visceral early
lethality (CAVE) multiplex syndrome. Am $₹ \mathrm{Med}$ Genet lethality (CAVE)

3 Graham JM, Harris M, Frank JE, Little GA, Klein RZ. Congenital hypothalamic hamartoblastoma syndrome: natural history and genetic implications. In: Endocrine genetics and genetics of growth. New York: Alan Liss, 1985:163-74.

4 Finnigan DP, Clarren SK, Haas JE. Extending the PallisterHall syndrome to include other central nervous system malformations. Am $\mathcal{F}$ Med Genet 1991;4:395-400.

5 Meunke M, Ruchelli ED, Rorke LB, et al. On lumping and splitting: a fetus with clinical findings of the oral-facialdigital syndrome type VI, the hydrolethalus syndrome and the Pallister-Hall syndrome. Am $f$ Med Genet 1991;41:548-56.

6 Encha-Razavi F, Larroche JC, Roume J, et al. Congenital hypothalamic hamartoma syndrome: nosological discussion and minimum diagnostic criteria of a possibly familial form. Am 7 Med Genet 1992;42:44-50.

7 Golabi M, Kuller K, Cox K, Keilman K, Schonberg S. Pallister-Hall syndrome associated with an unbalanced chromosome translocation. Am $\mathcal{f}$ Hum Genet (Suppl) 1991;49:137.

8 Pallister PD, Hecht F, Herrmann J. Three additional cases of the congenital hypothalamic hamartoblastoma (PallisterHall) syndrome. Am $\mathcal{F}$ Med Genet 1989;33:500-1. 